\title{
Correction to: Oral Disease-Modifying Treatments for Relapsing Multiple Sclerosis: A Likelihood to Achieve No Evidence of Disease Activity or Harm Analysis
}

\author{
Dimitrios Papadopoulos ${ }^{1}$. Dimos-Dimitrios D. Mitsikostas ${ }^{2}$ (I)
}

Published online: 20 December 2018

๑) Springer Nature Switzerland AG 2018

\section{Correction to: CNS Drugs (2018) 32:1069-1078 https://doi.org/10.1007/s40263-018-0547-z}

Page 1069, Abstract, Results- the text that read:

The values for likelihood to achieve NEDA than experience any $\mathrm{AE}$ ratio $\left(\mathrm{LHH}_{(\mathrm{AE} / \mathrm{NEDA})}\right)$ were $3.9,6.8,12.5$ and 3.7, the likelihood to achieve NEDA than experience a SAE ratio $\left(\mathrm{LHH}_{(\mathrm{SAE} / \mathrm{NEDA})}\right)$ values were $3.5,15,23.5$ and 2.8 , and the likelihood to achieve NEDA versus discontinue treatment $\left(\mathrm{LHH}_{(\mathrm{AE}-\mathrm{D} / \mathrm{NEDA})}\right)$ values were 20.3, 4.3, 3.9 and 3.1 for cladribine, dimethyl-fumarate, fingolimod, and teriflunomide, respectively.

Should read:

The values for likelihood to achieve NEDA than experience any $\mathrm{AE}$ ratio $\left(\mathrm{LHH}_{(\mathrm{AE} / \mathrm{NEDA})}\right)$ were $3.5,6.8,12.5$ and 2.6 , the likelihood to achieve NEDA than experience a SAE ratio $\left(\mathrm{LHH}_{(\mathrm{SAE} / \mathrm{NEDA})}\right)$ values were 13.0, 3.5, 23.5 and 2.7 , and the likelihood to achieve NEDA versus discontinue treatment $\left(\mathrm{LHH}_{(\mathrm{AE}-\mathrm{D} / \mathrm{NEDA})}\right)$ values were 17.7, 6.5, 4.6 and 3.0 for cladribine, dimethyl-fumarate, fingolimod, and teriflunomide, respectively.

The original article can be found online at https://doi.org/10.1007/ s40263-018-0547-z.

Dimos-Dimitrios D. Mitsikostas

dmitsikostas@med.uoa.gr

1 Multiple Sclerosis Centre and Neurology Section, Athens Medical Centre - Paleo Phaliro Clinic, 175-62 Athens, Greece

2 1st Neurology Department, Aeginition Hospital, Medical School, National and Kapodistrian University of Athens, 72-74 V. Sofia's Avenue, 11528 Athens, Greece
Page 1073, column 1, lines 9 to 12-the text that read:

NEDA was evaluated as the proportion of patients free of relapses, 3-month confirmed disability progression, and free of new or newly enlarging T2 lesion and Gadolinium enhancing lesions.

Should read:

NEDA was evaluated as the proportion of patients free of relapses and 3-month confirmed disability progression, and free of new and newly enlarging T2 lesion and Gadoliniumenhancing lesions.

Page 1073, column 2, section 3.2, line 2-the text that read: ... eight (95\% CI 5.3-11.5) for DMF ...

Should read:

... eight (95\% CI 5.0-11.9) for DMF ...

Page 1074, column 1, section 3.3, lines 7 to 12 -the text that read:

The $\mathrm{NNTH}_{\mathrm{AE}}$ values were 15 (95\% CI 7.8 to 65.2$)$ for cladribine, 52 (95\% CI 23.6 to - 270.1) for DMF, 68 (95\% CI 27.7 to -153.1 ) for fingolimod, and 44 (95\% CI 14.6 to - 44.2) for teriflunomide, indicating that fingolimod has the most and cladribine the least favorable safety profile with regard to the appearance of any AE (Table 4).

Should read:

The $\mathrm{NNTH}_{\mathrm{AE}}$ values were 14 (95\% CI 7.7 to 56.2) for cladribine, 52 (95\% CI 23.6 to - 270.1) for DMF, 68 (95\% CI 27.7 to -153.1 ) for fingolimod, and 31 (95\% CI 12.8 to 79.2) for teriflunomide, indicating that fingolimod has the most and cladribine the least favorable safety profile with regard to the appearance of any $\mathrm{AE}$ (Table 4). 
Page 1074, column 1, section 3.3, lines 15 to 19 -the text that read:

Nevertheless, with regard to the AEs that led to treatment discontinuation, the $\mathrm{NNTH}_{\mathrm{AE}-\mathrm{D}}$ was most favorable for cladribine (72 (95\% CI 27.9 to -129.5$])$ and least favorable for fingolimod (21 [95\% CI 12.6 to 54.1]) (Table 4).

Should read:

Nevertheless, with regard to the AEs that led to treatment discontinuation, the $\mathrm{NNTH}_{\mathrm{AE}-\mathrm{D}}$ was most favorable for cladribine (71 (95\% CI 27.9 to - 129.5]) and least favorable for fingolimod (28 [95\% CI 15.0 to 191.6]) (Table 4).
Page 1074 , column 2 , section 3.4 , lines 8 to 12 -the text that read:

Nevertheless, calculating the likelihood to achieve NEDA versus discontinue treatment due to an $\mathrm{AE}$ cladribine has the most favourable efficacy versus risk profile $\left(\mathrm{LHH}_{(\mathrm{AE}-\mathrm{D} / \mathrm{NEDA})}\right.$ 20.3 [95\% CI 7.03-37.48]).

Should read:

Nevertheless, calculating the likelihood to achieve NEDA versus discontinue treatment due to an $\mathrm{AE}$ cladribine has the most favourable efficacy versus risk profile $\left(\mathrm{LHH}_{(\mathrm{AE}-\mathrm{D} / \mathrm{NEDA})}\right.$ 17.7 [95\% CI 7.03-37.48]).

Table 2 that read:

Table 2 Source data

\begin{tabular}{|c|c|c|c|c|c|c|c|c|}
\hline \multirow[t]{2}{*}{ Treatment arm } & \multicolumn{2}{|c|}{ Cladribine } & \multicolumn{2}{|c|}{ Dimethyl-fumarate } & \multicolumn{2}{|c|}{ Fingolimod } & \multicolumn{2}{|c|}{ Teriflunomide } \\
\hline & Active & Placebo & Active & Placebo & Active & Placebo & Active & Placebo \\
\hline \multicolumn{9}{|c|}{ Patients that achieved NEDA } \\
\hline Proportion $(n)$ & $178 / 402$ & $60 / 379$ & $132 / 511^{\mathrm{a}}$ & $43 / 356^{\mathrm{a}}$ & $213 / 783$ & $65 / 773$ & $82 / 358$ & $52 / 363$ \\
\hline Percentage $(\%)$ & 44.3 & 15.8 & 26 & 12 & 27.2 & 8.4 & 22.9 & 14.3 \\
\hline $\begin{array}{l}\text { Patients in safety } \\
\text { analysis }(n)\end{array}$ & 433 & 437 & 769 & 771 & 783 & 773 & 360 & 358 \\
\hline $\begin{array}{l}\text { Proportion of } \\
\text { patients with } \\
\text { any } \operatorname{AE}(n)\end{array}$ & $347 / 433$ & $319 / 437$ & $733 / 769$ & $720 / 771$ & $751 / 783$ & $730 / 773$ & $325 / 360$ & $315 / 358$ \\
\hline $\begin{array}{l}\text { Proportion of } \\
\text { patients with } \\
\text { any SAE }(n)\end{array}$ & $36 / 433$ & $28 / 437$ & $135 / 769$ & $165 / 771$ & $96 / 783$ & $101 / 773$ & $57 / 360$ & $46 / 358$ \\
\hline $\begin{array}{l}\text { Proportion of } \\
\text { patients that } \\
\text { discontinued } \\
\text { treatment due } \\
\text { to an } \mathrm{AE}(n)\end{array}$ & $15 / 433$ & $9 / 437$ & $109 / 769$ & 93/771 & $101 / 783$ & $62 / 773$ & $39 / 360$ & $29 / 358$ \\
\hline References & \multicolumn{2}{|l|}{$[11,21]$} & \multicolumn{2}{|c|}{$[12,13,18,19]$} & \multicolumn{2}{|c|}{$[14,15,20]$} & \multicolumn{2}{|l|}{$[16,22]$} \\
\hline
\end{tabular}

$A E$ adverse event, $M R I$ magnetic resonance imaging, NEDA no evidence of disease activity, $S A E$ serious adverse event

${ }^{a}$ Dimethyl-fumarate and placebo patients used for the NEDA analysis (MRI cohort) were the subpopulation of patients from DEFINE and CONFIRM with MRI data 
Should read:

Table 2 Source data

\begin{tabular}{|c|c|c|c|c|c|c|c|c|}
\hline \multirow[t]{2}{*}{ Treatment arm } & \multicolumn{2}{|c|}{ Cladribine } & \multicolumn{2}{|c|}{ Dimethyl-fumarate } & \multicolumn{2}{|l|}{ Fingolimod } & \multicolumn{2}{|c|}{ Teriflunomide } \\
\hline & Active & Placebo & Active & Placebo & Active & Placebo & Active & Placebo \\
\hline \multicolumn{9}{|c|}{ Patients that achieved NEDA } \\
\hline Proportion $(n)$ & $178 / 402$ & $60 / 379$ & $90 / 345^{a}$ & $41 / 347^{\mathrm{a}}$ & $213 / 783$ & $65 / 773$ & $82 / 358$ & $52 / 363$ \\
\hline Percentage (\%) & 44.3 & 15.8 & 26.1 & 11.8 & 27.2 & 8.4 & 22.9 & 14.3 \\
\hline $\begin{array}{l}\text { Patients in safety } \\
\text { analysis }(n)\end{array}$ & 430 & 435 & 769 & 771 & 783 & 773 & 358 & 360 \\
\hline $\begin{array}{l}\text { Proportion of } \\
\text { patients with } \\
\text { any } \mathrm{AE}(n)\end{array}$ & $347 / 430$ & $319 / 435$ & $733 / 769$ & $720 / 771$ & $751 / 783$ & $730 / 773$ & $325 / 358$ & $315 / 360$ \\
\hline $\begin{array}{l}\text { Proportion of } \\
\text { patients with } \\
\text { any SAE }(n)\end{array}$ & $36 / 430$ & $28 / 435$ & $135 / 769$ & $165 / 771$ & $96 / 783$ & $101 / 773$ & $57 / 358$ & $46 / 360$ \\
\hline $\begin{array}{l}\text { Proportion of } \\
\text { patients that } \\
\text { discontinued } \\
\text { treatment due } \\
\text { to an } \mathrm{AE}(n)\end{array}$ & $15 / 430$ & $9 / 435$ & $109 / 769$ & $93 / 771$ & $98 / 783$ & $69 / 773$ & $39 / 358$ & $29 / 360$ \\
\hline References & {$[11,21]$} & & $\begin{array}{l}{[12,13,18,} \\
19]\end{array}$ & & {$[14,15,20]$} & & {$[16,22]$} & \\
\hline
\end{tabular}

$A E$ adverse event, $M R I$ magnetic resonance imaging, NEDA no evidence of disease activity, $S A E$ serious adverse event

${ }^{a}$ Dimethyl-fumarate and placebo patients used for the NEDA analysis (MRI cohort) were the subpopulation of patients from DEFINE and CONFIRM with MRI data

Table 3 that read:

Table 3 Numbers needed to treat for one patient to achieve no evidence of disease activity $\left(\mathrm{NNTB}_{\mathrm{NEDA}}\right)$

\begin{tabular}{lllll}
\hline & Cladribine (CLARITY) & $\begin{array}{l}\text { Dimethyl-fumarate (pooled } \\
\text { DEFINE+CONFIRM) }\end{array}$ & $\begin{array}{l}\text { Fingolimod (pooled } \\
\text { FREEDOMS + FREEDOMS II) }\end{array}$ & $\begin{array}{l}\text { Teriflunomide } \\
\text { (TEMS0) }\end{array}$ \\
\hline Total $(n)$ & 812 & 867 & 1561 & 721 \\
RR & 2.79 & 2.13 & 3.23 & 1.59 \\
$95 \% \mathrm{CI}$ & $2.16-3.61$ & $1.55-2.93$ & $2.5-4.2$ & $1.16-2.19$ \\
$p$ value & $<0.0001$ & $<0.0001$ & $<0.0001$ & $<0.0035$ \\
AR & 0.28 & 0.13 & 0.19 & 0.08 \\
NNTB & 4 & 8 & 6 & 12 \\
$95 \%$ CI & $2.9-4.5$ & $5.3-11.9$ & $4.4-6.6$ & $7.0-34.1$ \\
\hline
\end{tabular}

$A R$ attributable risk (proportion of patients achieving NEDA in active group minus proportion of patients achieving NEDA in placebo group), $C I$ confidence interval, $N E D A$ no evidence of disease activity, $N N T B_{N E D A}$ number of patients needed to treat for a patient to achieve NEDA, $R R$ relative risk (proportion of patients achieving NEDA in active group out of the total patients in the active group over the proportion of patients achieving NEDA in placebo group out of the total patients in placebo group) 
Should read:

Table 3 Numbers needed to treat for one patient to achieve no evidence of disease activity $\left(\mathrm{NNTB}_{\mathrm{NEDA}}\right)$

\begin{tabular}{lllll}
\hline & Cladribine (CLARITY) & $\begin{array}{l}\text { Dimethyl-fumarate (pooled } \\
\text { DEFINE+CONFIRM) }\end{array}$ & $\begin{array}{l}\text { Fingolimod (pooled FREEDOMS + } \\
\text { FREEDOMS II) }\end{array}$ & $\begin{array}{l}\text { Teriflunomide } \\
\text { (TEMS0) }\end{array}$ \\
\hline Total $(n)$ & 781 & 692 & 1556 & 721 \\
RR & 2.79 & 2.13 & 3.23 & 1.59 \\
$95 \%$ CI & $2.16-3.61$ & $1.55-2.93$ & $2.5-4.2$ & $1.16-2.19$ \\
$p$ value & $<0.0001$ & $<0.0001$ & $<0.0001$ & $<0.0035$ \\
AR & 0.28 & 0.13 & 0.19 & 0.08 \\
NNTB & 4 & 8 & 6 & 12 \\
$95 \%$ CI & $2.9-4.5$ & $5.0-11.9$ & $4.4-6.6$ & $7.0-34.1$ \\
\hline
\end{tabular}

$A R$ attributable risk (proportion of patients achieving NEDA in active group minus proportion of patients achieving NEDA in placebo group), $C I$ confidence interval, $N E D A$ no evidence of disease activity, $N N T B_{N E D A}$ number of patients needed to treat for a patient to achieve NEDA, $R R$ relative risk (proportion of patients achieving NEDA in active group out of the total patients in the active group over the proportion of patients achieving NEDA in placebo group out of the total patients in placebo group)

Table 4 that read:

Table 4 Numbers needed to harm (NNTH) analysis of safety

\begin{tabular}{|c|c|c|c|c|}
\hline & $\begin{array}{l}\text { Cladribine } \\
\text { CLARITY }\end{array}$ & $\begin{array}{l}\text { DMF (pooled DEFINE } \\
\text { and CONFIRM) }\end{array}$ & $\begin{array}{l}\text { Fingolimod (pooled FREEDOMS } \\
\text { and FREEDOMS II) }\end{array}$ & $\begin{array}{l}\text { Teriflunomide } \\
\text { TEMSO }\end{array}$ \\
\hline $\mathrm{NNTH}_{\mathrm{AE}}$ & 15 & 52 & 68 & 44 \\
\hline $95 \%$ CI & $7.8-65.2$ & $\begin{array}{l}\text { NNTH } 23.6 \text { to } \infty \text { to } \\
\text { NNTB } 270.1^{\mathrm{a}}\end{array}$ & $\begin{array}{l}27.7 \text { to } \infty \text { to } \\
\text { NNTB } 153.1\end{array}$ & $\begin{array}{l}14.6 \text { to } \infty \text { to } \\
\text { NNTB } 44.2\end{array}$ \\
\hline $\mathrm{NNTH}_{\text {SAE }}$ & 53 & 27 & 125 & 34 \\
\hline $95 \% \mathrm{CI}$ & $\begin{array}{l}18.6 \text { to } \infty \text { to } \\
\text { NNTB } 64^{\mathrm{a}}\end{array}$ & $\begin{array}{l}12.8 \text { to } \infty \text { to } \\
\text { NNTB } 947.3^{\text {a }}\end{array}$ & $\begin{array}{l}24.3 \text { to } \infty \text { to } \\
\text { NNTB } 40^{\text {a }}\end{array}$ & $\begin{array}{l}12 / 3 \text { to } \infty \text { to } \\
\text { NNTB } 46.8^{\text {a }}\end{array}$ \\
\hline $\mathrm{NNTH}_{\mathrm{AE}-\mathrm{D}}$ & 72 & 48 & 21 & 37 \\
\hline $95 \%$ CI & $\begin{array}{l}27.9 \text { to } \infty \text { to } \\
\text { NNTB } 129.5^{\text {a }}\end{array}$ & $\begin{array}{l}18.2 \text { to } \infty \text { to } \\
\text { NNTB } 79.4^{\text {a }}\end{array}$ & $12.6-54.1$ & $\begin{array}{l}14 / 3 \text { to } \infty \text { to } \\
\text { NNTB } 64.7^{\text {a }}\end{array}$ \\
\hline
\end{tabular}

$A E$ adverse event, $A E-D$ adverse event leading to treatment discontinuation, $C I$ confidence interval, $D M F$ dimethyl-fumarate, $N N T B$ number of patients needed to treat for a patient to have a good outcome (to achieve no evidence of activity), $N N T H$ number of patients needed to treat for a patient to have a harmful outcome, $S A E$ serious adverse event. In some cases the harmful effect of the treatment leading to an AE was not significantly different from placebo at the $p 0.05$ level and resulted in the $95 \%$ CIs of the NNTH to include infinity $(\infty)$

${ }^{\text {a }}$ No significant difference between active treatment and placebo 
Should read:

Table 4 Numbers needed to harm (NNTH) analysis of safety

\begin{tabular}{lllll}
\hline & $\begin{array}{l}\text { Cladribine } \\
\text { CLARITY }\end{array}$ & $\begin{array}{l}\text { DMF (pooled DEFINE } \\
\text { and CONFIRM) }\end{array}$ & $\begin{array}{l}\text { Fingolimod (pooled FREEDOMS } \\
\text { and FREEDOMS II) }\end{array}$ & $\begin{array}{l}\text { Teriflunomide } \\
\text { TEMSO }\end{array}$ \\
\hline $\mathrm{NNTH}_{\mathrm{AE}}$ & 14 & 52 & 68 & 31 \\
$95 \% \mathrm{CI}$ & $7.7-56.2$ & NNTH 23.6 to $\infty$ to & 27.7 to $\infty$ to & 12.8 to $\infty$ to \\
& & NNTB $270.1^{\mathrm{a}}$ & NNTB 153.1 & 32 \\
$\mathrm{NNTH}_{\mathrm{SAE}}$ & 52 & 27 & 125 & 12.1 to $\infty$ to \\
$95 \% \mathrm{CI}$ & 18.6 to $\infty$ to & 12.8 to $\infty$ to & 24.3 to $\infty$ to & NNTB $50.5^{\mathrm{a}}$ \\
& NNTB $64^{\mathrm{a}}$ & NNTB $947.3^{\mathrm{a}}$ & 28 & 36 \\
$\mathrm{NNTH}_{\mathrm{AE}-\mathrm{D}}$ & 71 & 48 & $15-191.6$ & 14.0 to $\infty$ to \\
$95 \% \mathrm{CI}$ & 27.7 to $\infty$ to & 18.2 to $\infty$ to & & NNTB $69.4^{\mathrm{a}}$ \\
\hline
\end{tabular}

$A E$ adverse event, $A E-D$ adverse event leading to treatment discontinuation, $C I$ confidence interval, $D M F$ dimethyl-fumarate, $N N T B$ number of patients needed to treat for a patient to have a good outcome (to achieve no evidence of activity), $N N T H$ number of patients needed to treat for a patient to have a harmful outcome, $S A E$ serious adverse event. In some cases the harmful effect of the treatment leading to an AE was not significantly different from placebo at the $p 0.05$ level and resulted in the $95 \%$ CIs of the NNTH to include infinity $(\infty)$

${ }^{a}$ No significant difference between active treatment and placebo

Figure 1 that was:

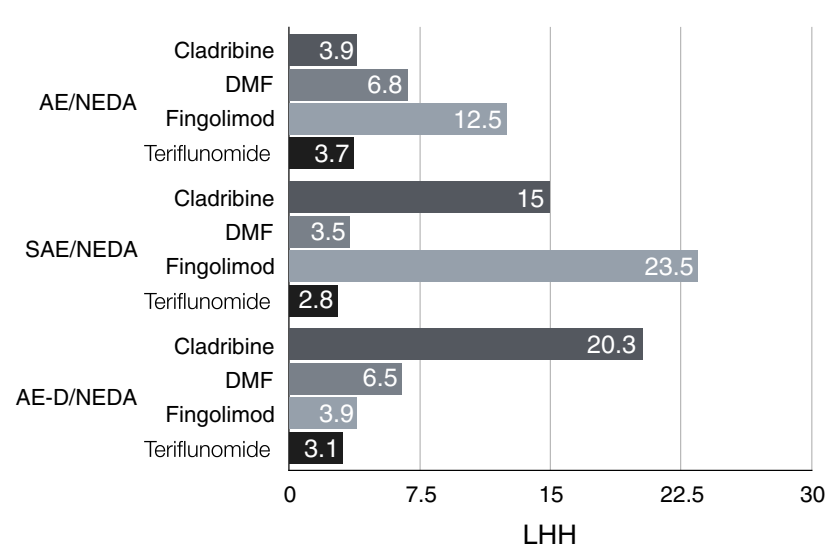

Should read:

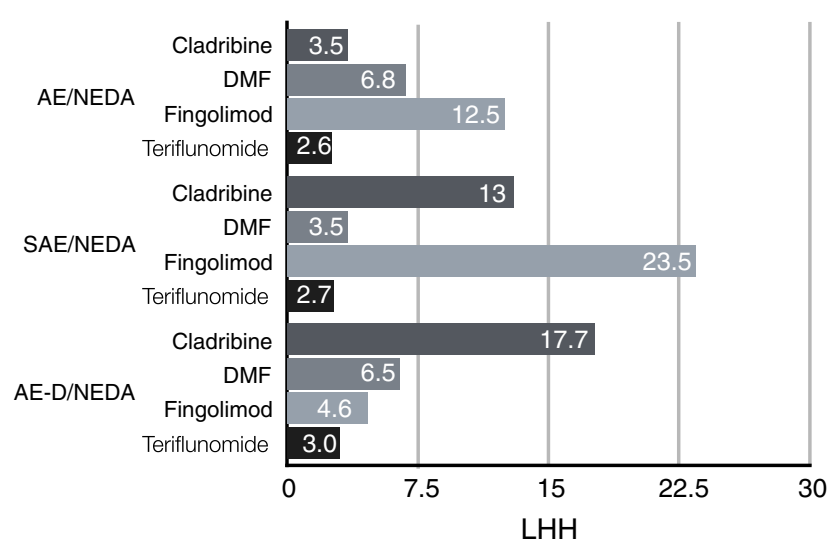

